\author{
Marquette University \\ e-Publications@Marquette
}

8-2013

\title{
Recyclable Synthesis, Characterization, and Antimicrobial Activity of Chitosan-based Polysaccharide Composite Materials
}

Chieu D. Tran

Marquette University, chieu.tran@marquette.edu

Simon Duri

Marquette University, simon.duri@marquette.edu

April Harkins

Marquette University, april.harkins@marquette.edu

Follow this and additional works at: https://epublications.marquette.edu/chem_fac

Part of the Chemistry Commons

\section{Recommended Citation}

Tran, Chieu D.; Duri, Simon; and Harkins, April, "Recyclable Synthesis, Characterization, and Antimicrobial Activity of Chitosan-based Polysaccharide Composite Materials" (2013). Chemistry Faculty Research and Publications. 256.

https://epublications.marquette.edu/chem_fac/256 
Marquette University

e-Publications@Marquette

\title{
Clinical Laboratory Science Faculty Research and Publications/College of Health Sciences
}

This paper is NOT THE PUBLISHED VERSION; but the author's final, peer-reviewed manuscript. The published version may be accessed by following the link in the citation below.

Journal of Biomedical Materials Research, Part A, Vol. 101A, No. 8 (August 2013): 2248-2257. DOI. This article is (C) Wiley and permission has been granted for this version to appear in $\underline{\text { e- }}$ Publications@Marquette. Wiley does not grant permission for this article to be further copied/distributed or hosted elsewhere without the express permission from Wiley.

\section{Recyclable synthesis, characterization, and antimicrobial activity of chitosan-based polysaccharide composite materials ${ }^{\dagger}$}

\author{
Chieu D. Tran
}

Department of Chemistry, Marquette University, P. O. Box 1881, Milwaukee, Wisconsin Simon Duri

Department of Chemistry, Marquette University, P. O. Box 1881, Milwaukee, Wisconsin April L. Harkins

Department of Chemistry, Marquette University, P. O. Box 1881, Milwaukee, Wisconsin

\section{Abstract}

We have successfully developed a simple and totally recyclable method to synthesize novel, biocompatible, and biodegradable composite materials from cellulose (CEL) and chitosan (CS). In this method, $\left[\mathrm{BMIm}^{+} \mathrm{Cl}^{-}\right]$, an ionic liquid (IL), was used as a green solvent to dissolve and synthesize the [CEL+CS] composites. Since, the IL can be removed from the composites by washing them with water, and recovered by distilling the washed solution, the method is totally recyclable. Spectroscopic and imaging techniques including XRD, FTIR, NIR, and SEM were used 
to monitor the dissolution, to characterize and to confirm that CEL and CS were successfully regenerated. More importantly, we have successfully demonstrated that [CEL+CS] composite is particularly suited for many applications including antimicrobial property. This is because the composites have combined advantages of their components, namely superior chemical and mechanical stability (from CEL) and bactericide (from CS). Results of tensile strength measurements clearly indicate that adding CEL into CS substantially increase its tensile strength. Up to $5 \times$ increase in tensile strength can be achieved by adding $80 \%$ of CEL into CS. Results of in vitro antibacterial assays confirm that CS retains its antibacterial property in the composite. More importantly, the composites reported here can inhibit growth of wider range of bacteria than other CS-based materials prepared by conventional methods; that is over $24 \mathrm{~h}$ period, the composites substantially inhibited growth of bacteria such as MRSA, VRE, S. aureus, E. coli. These are bacteria that are often found to have the highest morbidity and mortality associated with wound infections.

\section{INTRODUCTION}

Hemorrhage is the leading cause of death from battlefield trauma and the second leading cause of death in the civilian community. It accounts for the vast majority of operating room deaths among trauma patients. In addition, the leading cause of reoperation in trauma patients is incomplete hemostasis in previously recognized injuries. The development of novel and/or improved methods for hemorrhage control including hemostatic dressings and rapid wound healing is not only important but also critical.

Over the last decade, many hemostatic agents and dressings have been tested with variable degrees of success. The most notable success is a sponge dressing based on chitosan (CS) ${ }^{1-6} \mathrm{CS}$, a linear polysaccharide, is derived from the $\mathrm{N}$-deacetylation of chitin which is the second most abundant naturally occurring polysaccharide found in the exoskeletons of crustaceans such as crabs and shrimp and cell walls of fungi [the most abundant is cellulose (CEL)]. It is inexpensive, readily available, biodegradable, biocompatible, and is known to possess unique properties including wound healing, hemostasis and antibacterial activity ${ }^{1-6}$ It is also known to be an effective drug carrier. ${ }^{7-9}$ These unique properties make CS particularly suited to heal wounds. This is because its unique properties work in concert to synergistically address all phases of wound healing, namely its hemostasis to stop hemorrhage, its bactericide for debridement, its wound healing ability to keep the wound moist and well ventilated for fast healing, and its drug delivery to encapsulate, stabilize, and deliver drugs to promote proliferation (or granulation tissue formation) and matrix formation and remodeling.

Unfortunately, in spite of its clear advantages, there are drawbacks, which limit applications of current CS-based dressing products. For example, it is not possible to dissolve CS in organic solvents because it has a rigid crystalline structure due to intra- and inter-molecular hydrogen bonds. ${ }^{10-12}$ As a consequence, an acid such as acetic acid is required to break hydrogen bonds to facilitate dissolution. Subsequent neutralization with a base solution is then needed. Such a procedure is not only costly and time consuming, but also may lead to acid induced changes in the structure of CS. ${ }^{13,14}$ Furthermore, CS has rather poor rheological properties and will undergo extensive swelling in water. This makes it structurally too weak to be used by itself in any application. To increase the structural strength of CS products, attempts have been made to crosslink CS chains with a crosslinking agent or convert its functional group via a chemical reaction. In fact, all current CS-based biochemical and medical devices are based on these methods. ${ }^{15-19}$ For examples, CS-based bandages currently available commercially include Tegasorb by $3 \mathrm{M}$, Chitapack $\mathrm{C}$ by Eisai Corp (Japan) and Hemcom bandages by HemCon Corp. Tegasorb bandages contain CS particles whereas Chitapack C and HemCon bandages are based on CS films grafted to man-made polymers. ${ }^{15-19}$ The rather complicated, costly, and multistep process currently used, that is, it involves the use of environmentally harmful chemicals and solvents, and man-made polymers to strengthen its structure, is not desirable as it may inadvertently alter its unique properties, making the CS-based composite materials less biocompatible and toxic, and removing or lessening its unique properties. A new 
method which can effectively dissolve CS not at high temperature by strong acid/base but rather by recyclable "green" solvent and to improve the structural strength of CS products not by chemical modification with synthetic chemicals and/or polymers but rather by use of naturally occurring biopolymers such as CEL, is particularly needed. Such demand makes recent report on ability of a simple ionic liquid, butyl methylimmidazolium chloride to dissolve up to $10 \%(\mathrm{w} / \mathrm{w})$ of CEL, particularly important. ${ }^{20-23}$

Butyl methylimmidazolium chloride ([BMIm $\left.\left.{ }^{+} \mathrm{Cl}^{-}\right]\right)$belongs to a group of compounds known as ionic liquids (ILs). ${ }^{24}$

${ }^{29}$ ILs are organic salts that are liquid at room temperature. They have unique chemical and physical properties, including being air and moisture stable, a high solubility power, and virtually no vapor pressure. Because of these properties, they can serve as a "GREEN." recyclable alternative to the volatile organic compounds that are traditionally used as industrial solvents. Because of their advantages, ILs have been used for applications, which are not possible with other chemicals. For example, the high solubility power, and the fact that the solvation ability of ILs can readily be tuned and adjusted by appropriately modifying structure of either cation and/or anion. This feature makes it possible to use ILs to dissolve many different classes of inorganic and organic compounds. In fact, as described earlier, IL such as $\left[\mathrm{BMIm}^{+} \mathrm{Cl}^{-}\right]$can dissolve up to $10 \%(\mathrm{w} / \mathrm{w})$ of $\mathrm{CEL}^{20-23}$ This discovery is of particular significance as it makes it possible for the first time that CEL can be dissolved, regenerated, and chemically modified by use of a simple and green solvent, which is not only inexpensive but also has high solubility power and low toxicity. Recently, it was found that $\left[\mathrm{BMIm}^{+} \mathrm{Cl}^{-}\right]$can also dissolve $\mathrm{CS}$ as well. $^{20-23}$

The fact that the same solvent can effectively dissolve CEL and CS is of extreme importance as it offers possibility to develop a totally recyclable method to synthesize novel, biocompatible, and high performance polysaccharide composite materials containing CEL and CS for use as bandage. The method is synergistic because composite material will have combined advantages of their components, namely superior chemical stability and mechanical strength (from CEL) and the ability to stop bleeding, clean, and heal wounds, to kill bacteria and to deliver drug (from CS).

The information presented is indeed provocative and clearly indicate that it is possible to develop a novel and green method to synthesize a high performance polysaccharide composite material from CS and CEL, which is not only biocompatible but also has combined advantages of its components, namely mechanical strength (from CEL), excellent absorber for pollutants, drug delivery, excellent bactericide, and hemostasis activity (from CS). Such considerations prompted us to initiate this study, which aims to hasten the breakthrough by systematically and revolutionarily exploit advantages of IL, a green solvent, to develop a novel, simple, pollution-free and totally recyclable method to dissolve CEL and CS, without using any harmful, volatile organic solvents and/or strong acid and base, for the synthesis of polysaccharide ecocomposite materials containing CEL and CS, and to demonstrate that these materials are not only fully biocompatible but also superior to currently available bandages with respect to wound cleaning and healing, hemostasis, and bactericide. The results of our initial investigation are reported herein.

\section{MATERIALS AND METHODS}

\section{Materials}

CEL (microcrystalline powder) and CS ( $M_{\mathrm{w}} \approx 310-375 \mathrm{kDa}, 75 \%$ degree of deacetylation, Sigma-Aldrich), were used as received. 1-methylimidazole and 1-chlorobutane, obtained from Alfa Aesar, were further purified by vacuum and normal distillation, respectively.

Near-infrared (NIR) spectra were taken on a home-built NIR spectrometer. ${ }^{30,31}$ FTIR spectra were measured on a PerkinElmer 100 spectrometer at $2 \mathrm{~cm}^{-1}$ resolution with either $\mathrm{KBr}$ or by a ZnSe single reflection ATR accessory 
(Pike Miracle ATR). X-ray diffraction (XRD) measurements were taken on a Rigaku MiniFlex II diffractometer equipped with a $\mathrm{Cu} \mathrm{K} \alpha$ source. Tensile strength measurements were performed on an Instron Tensile Tester.

The ionic liquid, 1-butyl 3-methylimidazolium chloride $\left[\mathrm{BMIm}^{+} \mathrm{Cl}^{-}\right]$was synthesized from 1-chlorobutane and 1methylimidazole based on the method previously used in our lab. ${ }^{32,33}$

\section{Preparation of CEL, CS, and [CEL+CS] composite films}

Homogeneous viscous solutions of $\mathrm{CEL}, \mathrm{CS}$, or their composite mixtures were obtained by dissolving the polysaccharides in $\left[\mathrm{BMIm}^{+} \mathrm{Cl}^{-}\right]$ionic liquid under magnetic stirring at $100-110^{\circ} \mathrm{C}$. Dissolution was performed in a $50 \mathrm{~mL}$ 3-neck round bottomed flask under $\mathrm{Ar}$ or $\mathrm{N}_{2}$ atmosphere. For example, $15.0 \mathrm{~g}$ of $\left[\mathrm{BMIm}^{+} \mathrm{Cl}^{-}\right]$ionic liquid was weighed into a $50 \mathrm{~mL}$ 3-neck round bottomed flask. CS $(0.15 \mathrm{~g})$ or CEL was added to the flask and the mixture stirred at about $200 \mathrm{rpm}$ at $100^{\circ} \mathrm{C}$ until the CS or CEL had completely dissolved. A second portion of 0.15 $\mathrm{g}$ of CS or CEL was added to the flask and completely dissolved. Finally, a third portion of $0.15 \mathrm{~g}$ of CS or CEL was dissolved, bringing the total wt \% of the polysaccharides in the ionic liquid to 3\%. (Q3) The CS and CEL were dissolved in small portions. Each portion was $\sim 1 \mathrm{wt} \%$ of the ionic liquid. Each portion was completely dissolved before the next portion was added. Dissolution of $1 \%$ portions of CS and CEL was continued until the desired concentration has been reached. For composite films, CEL was dissolved to the desired concentration first before dissolving CS. Using this procedure, solutions of CEL [containing up to $10 \% \mathrm{w} / \mathrm{w}$ (of IL)], CS (up to $4 \%$ $\mathrm{w} / \mathrm{w}$ ) and composite solutions containing CEL and CS in various proportions were prepared in about $6-8 \mathrm{~h}$. Upon complete dissolution, the homogeneous solutions of the polysaccharides in $\left[\mathrm{BMIm}^{+} \mathrm{Cl}^{-}\right]$were cast in PTFE moulds on Mylar sheets to produce thin films of about $105 \times 79 \times 3 \mathrm{~mm}^{3}$ with different compositions and concentrations of CEL and CS. The films were then kept at room temperature for $24 \mathrm{~h}$ to allow the solutions to undergo gelation. Subsequently, the $\left[\mathrm{BMIm}^{+} \mathrm{Cl}^{-}\right]$remaining in the films was removed by washing the films in deionized water for 3 days. The films were washed by soaking them in deionized water and stirred at about $250 \mathrm{rpm}$. The ratio of water to gel film used during the washing process was about $50 \mathrm{~mL} / \mathrm{g}$ and the washing water was replenished with fresh deionized water once each day during the course of the 3-day washing period. The $\left[\mathrm{BMIm}{ }^{+} \mathrm{Cl}^{-}\right]$used was recovered from the washed aqueous solution by distillation. The regenerated [CEL+CS] composite materials were then dried at room temperature in a chamber with humidity controlled at $60 \%$. Drying time was found to be dependent on the thickness of the films but generally was in the range of 3-5 days. It was found that humidity control is important to ensure that the films do not become brittle and cracked during drying.

\section{In vitro antibacterial assays}

Two types of composite films were used in the pH controlled antibacterial assays. They were $100 \%$ CS film and 50:50 CS:CEL composite film. Both were air-dried type of films. Three different $\mathrm{pH}$ levels were used. These were $\mathrm{pH} 3.5,5.0$, and 7.0. The desired $\mathrm{pH}$ level was obtained by adjusting the $\mathrm{pH}$ of deionized water using either $0.01 \mathrm{M} \mathrm{HCl}$ or $0.01 \mathrm{M} \mathrm{NaOH}$. The dry films were cut into small strips of $\sim 25 \times 5 \mathrm{~mm}^{2}$. These strips were placed in vials containing $50 \mathrm{~mL}$ of water at the desired $\mathrm{pH}$ and were left overnight with gentle magnetic stirring. After the overnight treatment, the strips were taken out, placed flat on Mylar substrates and were dried in air at room temperature before they were tested for their antimicrobial action. No humidity control was employed in this drying step.

Antibacterial in vitro studies were analyzed with a turbidimetric method. The composite films were sterilized with UV light for $2.0 \mathrm{~h}$. The bacterial strains Escherichia coli (ATCC 8739), Staphylococcus aureus (ATCC 25923), methicillin resistant S. aureus (ATCC 33591), and vancomycin resistant Enterococcus faecalis (ATCC 51299) were maintained on blood agar at $4^{\circ} \mathrm{C}$. Inhibition of growth was modified according to previously published method.5 Briefly, bacterial cells were grown overnight in nutrient broth for $18-20 \mathrm{~h}$ at $37^{\circ} \mathrm{C}$ on an orbital shaker. The cells were diluted to a concentration of $\sim 5 \times 10^{6}$ cells $/ \mathrm{mL}$ in $5 \mathrm{~mL}$ of fresh culture medium. The $25 \times 5$ 
$\mathrm{mm}^{2}$ strips of composite were added to the culture vial. Aliquots of the cultures were taken at multiple time points within $24 \mathrm{~h}$ and the turbidity measured with a spectrophotometer (Molecular Devices, Sunnyvale, CA) at $570 \mathrm{~nm}$. Growth curves were performed in triplicate.

\section{RESULTS AND DISCUSSION}

\section{Synthesis and characterization of [CEL+CS] composite materials}

Synthesis: As shown in Scheme 1, $\left[\mathrm{BMIm}^{+} \mathrm{Cl}^{-}\right.$] solutions containing one (CEL or CS) and two components (CEL+CS) with varying amounts of each component were successfully prepared using procedure described in the experimental section. Thin films of CEL, CS or [CEL+CS] with different concentrations having different thicknesses were then casted onto either microscopic glass slides or Mylar films. The films underwent gelation when they were allowed to cool down to room temperature (henceforth referred to as Gel Films).

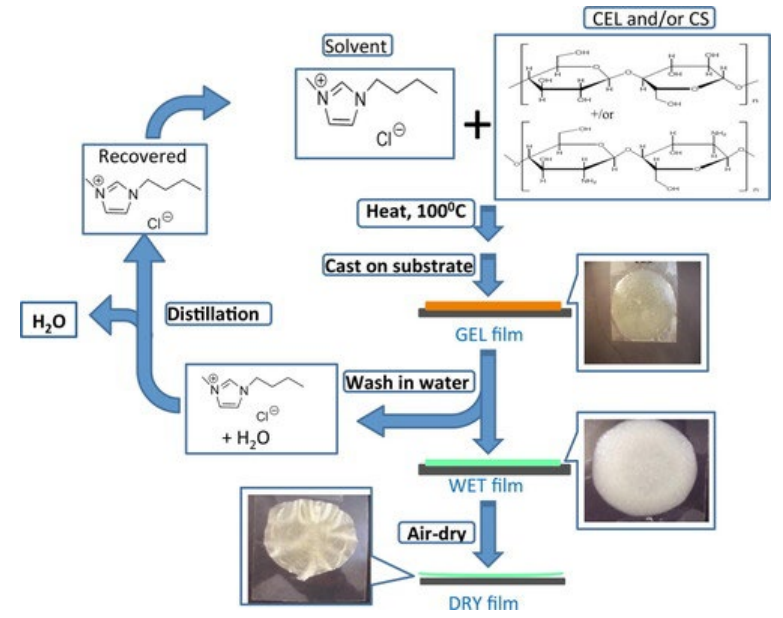

Scheme 1 Procedure used to prepare CS, CEL and [CEL+CS] composite materials.

The $\left[\mathrm{BMIm}^{+} \mathrm{Cl}^{-}\right]$in the Gel Films was then removed by soaking the films in water at room temperature for three days to yield "[ $\left[\mathrm{BMIm}^{+} \mathrm{Cl}^{-}\right]$-free" films (henceforth referred to as Wet Films). Finally, Dried Films were obtained when the Wet Films are allowed to dry in a chamber with humidity controlled at $60 \%$ to avoid any cracking during the drying period.

As shown in Scheme 1 images of films of two component [CEL+CS] casted right after the polysaccharides were dissolved in $\left[\mathrm{BMIm}^{+} \mathrm{Cl}^{-}\right]$, that is Gel Film, are shown in top right corner of the Scheme. After soaking in water for three days, $\left[\mathrm{BMIm}^{+} \mathrm{Cl}^{-}\right]$was removed from the gel film to yield corresponding Wet Films. Finally, Dried Films was obtained when the wet film was allowed to dry at room temperature.

X-ray diffraction (XRD), FTIR, and NIR techniques were employed to follow and confirm the dissolution process and to characterize the films. XRD spectra of microcrystalline CEL (pink curve), the CEL one-component Gel Film (orange curve), the corresponding Dried Film (green curve) as well as that of $\left[\mathrm{BMIm}^{+} \mathrm{Cl}^{-}\right.$] (blue curve) for reference are shown in Figure 1(A). Microscrystalline CEL exhibits diffraction peaks at $2 \theta=14.7^{\circ}$ and $16.3^{\circ}$, $22.5^{\circ}$, and $34.6^{\circ}$ for (101), (002), and (040) plane, respectively. These bands disappeared completely when the powder polysaccharide was dissolved in $\left[\mathrm{BMIm}^{+} \mathrm{Cl}^{-}\right]$. The disappearance of these bands together with the similarity between the spectrum of liquid $\left[\mathrm{BMIm}^{+} \mathrm{Cl}^{-}\right]$and that of the Gel Film clearly indicate that $\left[\mathrm{BMIm}^{+} \mathrm{Cl}^{-}\right]$ completely dissolved the polysaccharide. Similar results were also found for CS [Fig. 1(B)], namely, the fact that diffraction bands of the CS powder disappeared when they were dissolved in $\left[\mathrm{BMIm}^{+} \mathrm{Cl}^{-}\right]$, clearly indicate that the $\left[\mathrm{BMIm}^{+} \mathrm{Cl}^{-}\right]$also dissolved this polysaccharide completely as well. As expected, similar results were also 
obtained for two-component composite films containing [CEL+CS] of 10:3 composition (see blue curve in 1(A) and 1 (B) shows XRD spectra of 10:3 CEL:CS two-component film).
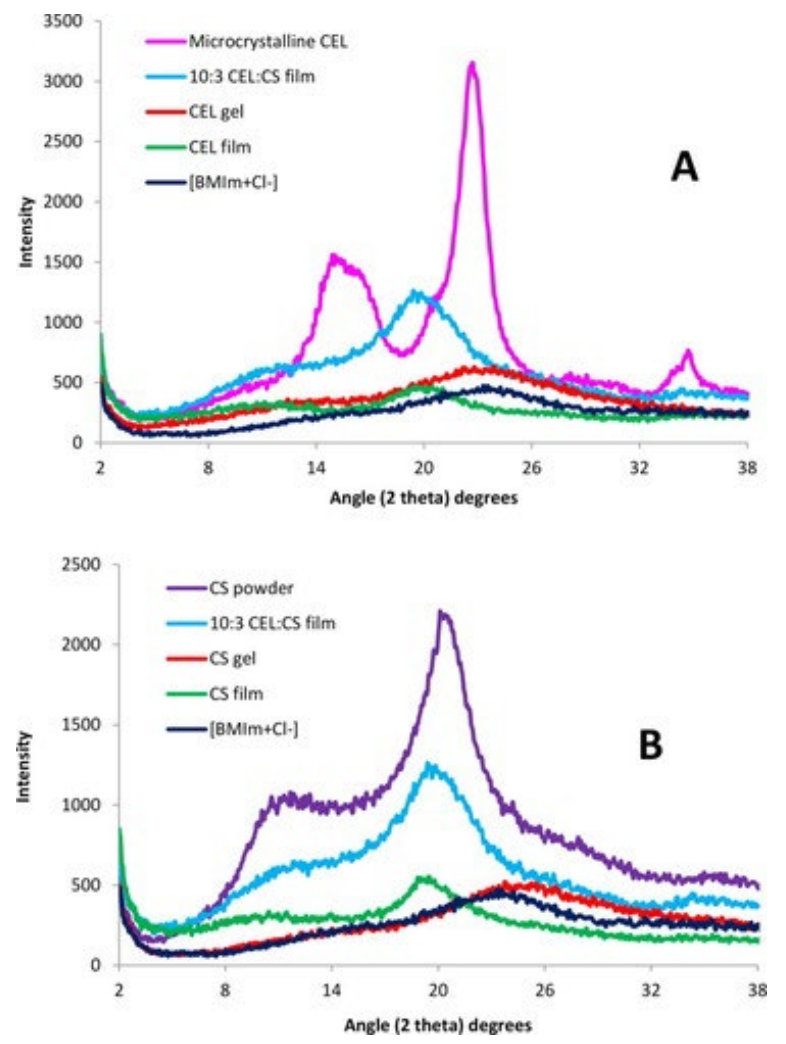

Figure $1 \mathrm{X}$-ray diffraction spectra of microcrystalline CEL, regenerated CEL film, CS powder, regenerated CS film, and $[\mathrm{CEL}+\mathrm{CS}]$ composite film.

The IL used in this work, $\left[\mathrm{BMIm}^{+} \mathrm{Cl}^{-}\right.$], is relatively nontoxic compared to other ILs (its EC-50 value is 897.47. ${ }^{34}$ Nevertheless, it is desirable to completely remove the IL from regenerated polysaccharide films to ensure the films are biocompatible. Since $\left[\mathrm{BMIm}^{+} \mathrm{Cl}^{-}\right]$is totally miscible with water (the $\log$ of $\mathrm{P}$, its octanolwater partition coefficient, is $-2.4^{35}$ ), it can be removed from Gel Films by washing the films with water. FTIR and NIR techniques were used to: 1 . confirm that $\left[\mathrm{BMIm}^{+} \mathrm{Cl}^{-}\right]$is completely removed from composite films when the films are washed with water; and 2. determine chemical composition of composite materials. As shown in Figure 2(A), overtone and combination bands of aliphatic $\mathrm{C}$ ?] $\mathrm{H}$ groups of the $\left[\mathrm{BMIm}^{+} \mathrm{Cl}^{-}\right]$can be clearly observed at 1388 and $1720 \mathrm{~nm}$. Since these bands are specific for $\left[\mathrm{BMIm}^{+} \mathrm{Cl}^{-}\right]$, they can be used as indicators to determine if the IL is present. NIR spectra of Gel Films of one-component CEL and CS samples as well as [CEL+CS] sample are also shown in Figure 2(A). Spectra of these Gel Films are very similar to that of $\left[\mathrm{BMIm}^{+} \mathrm{Cl}^{-}\right]$because the ionic liquid was the main component of these films. After washing with water to remove the IL, and drying, Dried Films of one-component CEL and CS samples were found to exhibit NIR spectra drastically different from those of their Gel Films shown in Figure 2(A) (together with the spectrum of $\left[\mathrm{BMIm}^{+} \mathrm{Cl}^{-}\right]$for reference). The fact that NIR spectra of the Dried Films [Fig. 2(B)] exhibit none of the indicator bands specific for $\left[\mathrm{BMIm}^{+} \mathrm{Cl}^{-}\right.$] clearly indicates that washing with water effectively and completely removed the IL from the films. Further confirmation of removal of the ionic liquid from the films can also be seen in Figure 2(C), which shows FTIR spectra of the same samples shown in 2(B), namely, $\left[\mathrm{BMIm}^{+} \mathrm{Cl}^{-}\right]$and Dried Films of CEL and CS. Again, none of the FTIR bands due to $\left[\mathrm{BMIm}^{+} \mathrm{Cl}^{-}\right]$were present in the spectra of both $\mathrm{CEL}$ and CS Dried Films. It was not possible to measure NIR and FTIR spectra of Wet Films because of strong background absorption of water. 

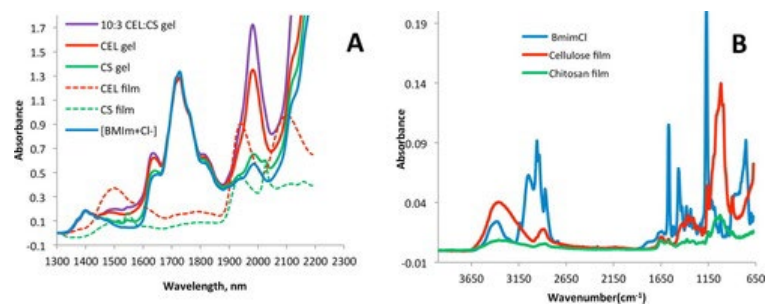

Figure 2 A: Near-IR spectra (A) [BMIm+Cl-] solution (solid blue), CEL Gel Film (solid red), CS Gel Film (solid green), [CEL + CS] Gel Film (solid violet), CEL Dried Film (dashed red), and CS Dried Film (dashed green); and B: FTIR spectra of $\left[\mathrm{BMIm}^{+} \mathrm{Cl}^{-}\right]$solution (blue), CEL Dried Film (red), and CS Dried Film (green).

The IL used was recovered by distilling the washed aqueous solution (the IL remained because its melting point (or decomposition temperature) is $>400^{\circ} \mathrm{C}$ ). The recovered $\left[\mathrm{BMIm}^{+} \mathrm{Cl}^{-}\right]$was dried under vacuum at $70^{\circ} \mathrm{C}$ overnight before reuse. It was found that at least $88 \%$ of $\left[\mathrm{BMIm}^{+} \mathrm{Cl}^{-}\right]$was recovered for reuse. As such, the synthetic method is recyclable because all chemicals used are fully recycled.

\section{Characterization of regenerated composite films}

Chemically, the regeneration of both CEL and CS was confirmed by FTIR spectroscopy. The FTIR spectrum of microcrystalline CEL [blue spectrum in Fig. 3(A)] exhibits three pronounced bands at around 3400, 2850-2900, and $890-1150 \mathrm{~cm}^{-1}$. These bands can be tentatively assigned to stretching vibrations of $\mathrm{O}$ ? $\mathrm{H}, \mathrm{C}$ ? $\mathrm{H}$, and ? O? group, respectively..$^{36-38}$ Since the Dried Film [red spectrum in 3(A)] also exhibits these three bands and is very similar to that of the microcrystalline $\mathrm{CEL}$, it is clear that CEL was completely regenerated by this synthetic method. Similarly, the FTIR spectrum of a CS Dried Film [green spectrum in 3(B)] is similar to the FTIR spectrum of the CS powder (blue spectrum) from which it was made. These spectra display characteristic CS bands around $3400 \mathrm{~cm}^{-1}$ (O?H stretching vibrations), $3250-3350 \mathrm{~cm}^{-1}$ (symmetric and asymmetric N?H stretching), $2850-2900 \mathrm{~cm}^{-1}$ (C? $\mathrm{CH}$ stretching), $1657 \mathrm{~cm}^{-1}$ (C?O, amide 1), $1595 \mathrm{~cm}^{-1}$ (NH deformation), 1380 $\mathrm{cm}^{-1}\left(\mathrm{CH}_{3}\right.$ symmetrical deformation), $1319 \mathrm{~cm}^{-1}$ (C?N stretching, amide III), and 890-1150 $\mathrm{cm}^{-1}$ (ether bonding). ${ }^{36-38}$ These results indicate that both CEL and CS were successfully regenerated by the synthetic method developed here without any chemical transformation.
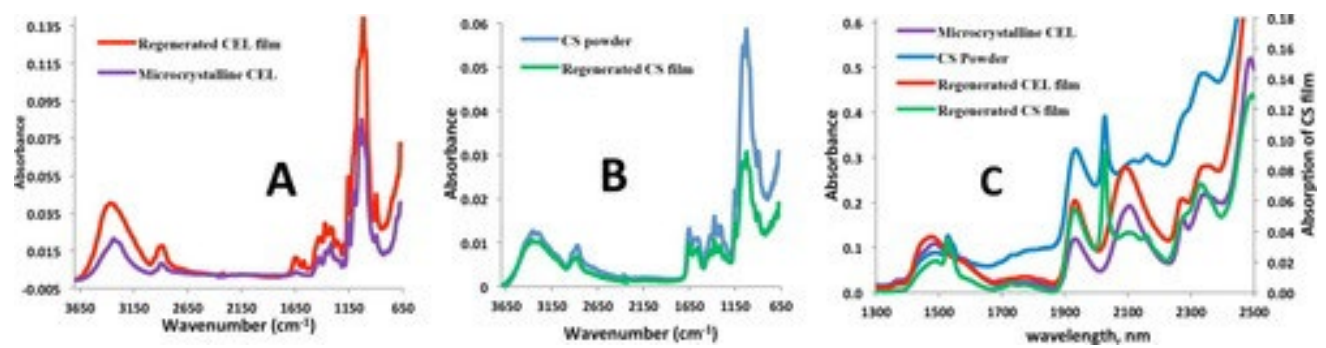

Figure 3 FTIR spectra (A and B) spectra of microcrystalline CEL (blue), regenerated CEL film (red), CS powder (blue), and regenerated CS film (green).

Results from NIR measurements further confirm regeneration of polysaccharide composite materials. Shown in Figure SI1 (of Supporting Information) are NIR spectra of microcrystalline CEL and regenerated CEL Dried Film, CS powder together with regenerated CS Dried Film. Again, the similarity between the NIR spectra of starting polysaccharides and regenerated polysaccharide further confirms that CEL and CS were successfully regenerated by this preparation method.

Properties, activities and responses of a sample are known to be dependent on its concentration (or rather on its active ingredient). It is, therefore, important to verify that in [CEL+CS] composite materials, each component is homogeneously distributed throughout the material in order to obtain desired and reproducible 
properties/activities/responses. Since electrical properties of CEL and CS are known to be somewhat different, homogeneity of composite materials containing two or more of these compounds can be determined by scanning electron microscope (SEM) because this technique is known to be dependent on electrical properties of a sample.

Analysis of the film materials by SEM reveals some interesting features about the texture and morphology of the materials. As expected, one-component CEL and CS [Figure 4(A,B), respectively] are homogeneous. Chemically, the only difference between CS and CEL is the few ?NH groups in the former (see Scheme 1). However, their structures, as recorded by the SEM, are substantially different. Specifically, while CS seems to exhibit smooth structure, CEL arranges itself into fibrous structure with fibers having diameter of about $~ 0.5-1.0$ micron. Interestingly, a 10:3 CEL:CS composite material [Fig. 4(C)] is not only homogeneous but it is more similar to structure of CS than that of CEL, namely, it has a rather smooth structure without any fibrous forms.

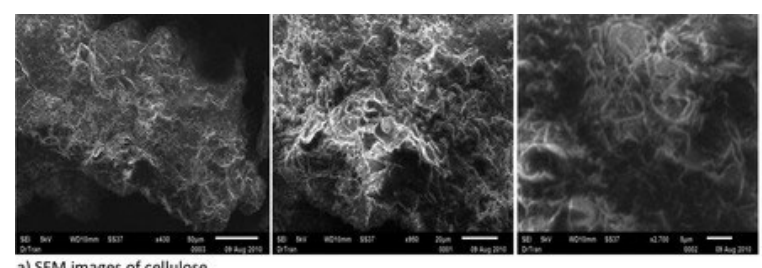

SEM images of cellulos

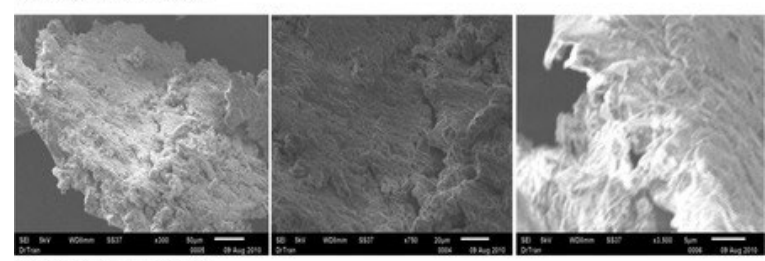

b) SEM images of chitosan

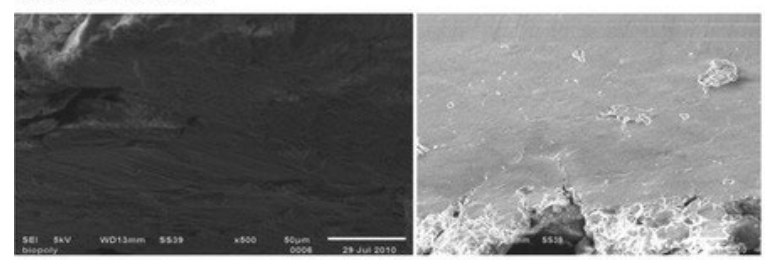

c) SEM images of cellulose/chitosan composite material

Figure 4 Scanning electron microscope images of (a) regenerated CEL film; (b) regenerated CS film, and (c) [CEL + CS] composite film.

\section{Properties of [CEL+CS] composite materials}

As described above, mechanical strength of CS is so poor that practically it cannot be used by itself for applications based on its unique properties. Measurements were made to determine tensile strength of pure CS film and (CS+CEL) composite films with different CEL concentrations in order to determine if by adding CEL into CS, [CEL+CS] composite material would have adequate mechanical strength for practical applications. Results obtained, shown in Figure 5, clearly indicate that adding CEL into CS substantially increase its tensile strength. For example, up to $5 \times$ increase in tensile strength can be achieved by adding $80 \%$ of CEL into CS, and that the tensile strength of the composite material can be adjusted to any value by adding judicious amount of CEL. More importantly, the tensile strengths of [CS+CEL] composite materials are comparable with those of existing CS materials including those prepared by either grafting or copolymerizing it with man-made polymers. ${ }^{39-42}$ Thus it is evidently clear that the [CEL+CS] composite materials have overcome the major hurdle currently imposed on utilizations of the materials, namely they have superior mechanical and rheological strength and still are able to retain their biocompatible and unique properties. 


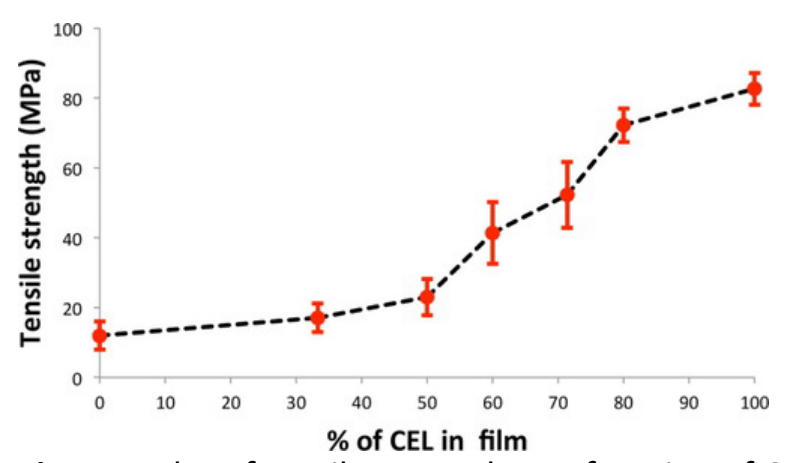

Figure 5 Plot of tensile strength as a function of CEL concentration in [CS + CEL] composite films.

Thermal gravimetric analysis (TGA) was also performed to determine thermal properties of the composite materials [Fig. 6(A)]. Also shown as an insert in Figure 6(A) is \% weight loss for composite films plotted as a function of CEL content in the films. Two main weight loss steps are seen in the Figure 6(A). The first weight loss occurs around $100^{\circ} \mathrm{C}$ and is predominant in low CEL containing films and is attributed to loss of moisture. The second major weight loss occurs from about $250^{\circ} \mathrm{C}$ to $350^{\circ} \mathrm{C}$. This weight loss is associated with chemical transformation leading to thermal degradation of the films. As illustrated by the insert in the figure, the onset of this degradation occurs at higher temperatures for high CEL containing films (greater than $70 \% \mathrm{CEL}$ ) than for low CEL containing films. In fact the decomposition temperature is generally the same from $0 \%$ CEL to about $70 \%$ CEL, thereafter it increased with increasing CEL content.
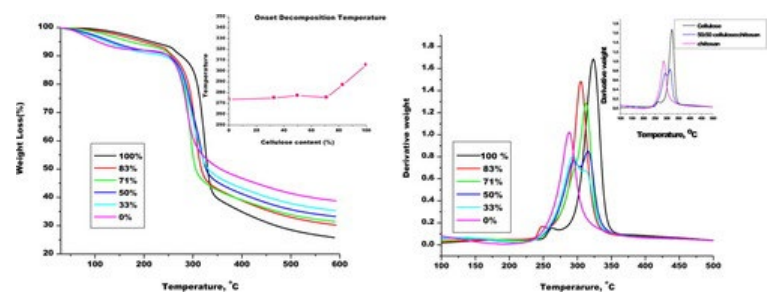

Figure 6 A: Thermal gravimetric analysis (TGA) weight loss curves of different compositions [CEL + CS] composite materials. (Insert: Plot of decomposition temperature as a function of CEL content in [CEL + CS] composite films); and B: Decomposition processes in [CEL + CS] composite films.

Figure 6(B) shows the derivative of the TGA weight loss curves, which shows in more detail the various steps in the degradation process. As illustrated in this figure, the $0 \%$ CEL (i.e., film with only CS) has only one major degradation step at about $287^{\circ} \mathrm{C}$. Hundred percent CEL also shows one major degradation step at about $323^{\circ} \mathrm{C}$. However, composite films have two major degradation steps. As illustrated for a 50:50 CEL:CS composite film in the insert in Figure $7(B)$, the two steps in the degradation of this composite film seem to correspond to that of $\mathrm{CS}$ and CEL, respectively. However, it was interesting to note that films with greater than $70 \%$ CEL showed only one degradation step. Amount of water remaining in the dried composite films can also be determined from the TGA curves. Specifically, by carefully analyzing change in the TGS curves at around $100^{\circ} \mathrm{C}$, it was found that there was at least $8 \mathrm{wt} \%$ of water remaining in the dried composite films.
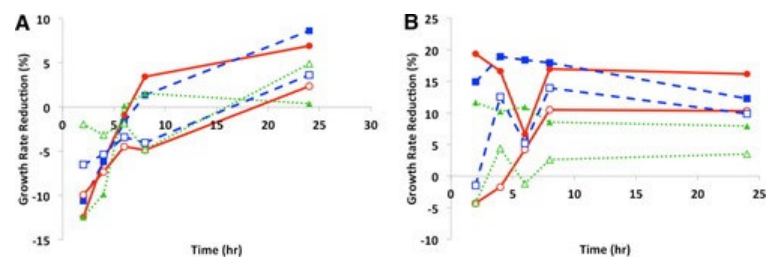

Figure 7 A-D: Growth reduction of MRSA (A), VRE (B), S. aureus (C), and E. coli (D) by [CEL + CS] composite materials; $100 \%$ CS (red circle), 40\% CS (green triangle), 29\% CS (blue square), $0 \%$ CS (i.e., 100\% CEL) (orange 
cross), and $100 \%$ lyophilized CS (purple diamond); and E and F: Growth reduction of MRSA (A) and E. coli (B) by $\mathrm{pH}$-treated [CEL + CS] composite materials; $100 \% \mathrm{CS}$ pH 3.5 (red, closed circle), pH 5.0 (blue, closed square), $\mathrm{pH}$ 7.0 (green, closed triangle), 50\% CS pH 3.5 (red, open circle), pH 5.0 (blue, open square), pH 7.0 (green, open triangle).

Taken together, results presented clearly indicate that we have successfully developed a novel and recyclable method to dissolve CEL and CS and to synthesize novel, biocompatible all polysaccharide composite materials containing CEL and CS. As expected, adding CEL to CS increases thermal stability and mechanical strength of the composite material. It is expected that the [CEL+CS] composite materials may have properties of both CEL and CS, namely, superior mechanical and rheological properties (from CEL) and bactericide (from CS). Initial evaluation of antibacterial ability of these composite materials is described in following section.

\section{In vitro antibacterial assays}

As described in the introduction section, CS-based composite materials previously synthesized by grafting and/or copolymerizing with man-made polymers have proven to have efficient antimicrobial activity. ${ }^{43,44}$ It is anticipated that the [CEL+CS] composite material synthesized here should also have antimicrobial activity. Reported optical density method was used to determine if the [CEL+CS] composite material synthesized here also has antimicrobial activity. Specifically, the bacteria were grown in the presence and absence of the composite material. Assays were carried out with composite materials with different compositions and/or $\mathrm{pH}$. Growth curves were measured by absorbance at $570 \mathrm{~nm}$ and growth reduction rates were determined as compared to bacterial growth in the absence of CS material (standard). It was found that in non-pH treated CS composites [Fig. 7(A-D)], all of the bacterial strains displayed decreased growth rates as compared to the standard when exposed to $100 \%$ CS material. MRSA (A) had the most inhibited growth at a reduction of $20 \%$ in the presence of $100 \% \mathrm{CS}$ at $24 \mathrm{~h}$, although within $8 \mathrm{~h}$ there was an apparent inhibitory effect. Further analysis showed a possible dose-dependent effect with the differing compositions of non-pH treated composite material for MRSA. In contrast, $S$. aureus (C) showed an inhibition at $8 \mathrm{~h}$, followed by a significant decrease in inhibition by $24 \mathrm{~h}$. VRE (B) also had a consistent growth rate reduction when exposed to $100 \%$ CS material, though not as much of an effect with the lyophilized $100 \%$ CS as was seen with MRSA and E. coli strains. E. coli (D) had a growth rate reduction of $18 \%$ for $100 \%$ CS and a $15 \%$ reduction with the $100 \%$ CS lyophilized composite at $24 \mathrm{~h}$. Overall, E. coli displayed consistent inhibition across all time points when incubated with either $100 \%$ CS composites. The importance of this finding is the range of bacteria that this composite is affecting.

To investigate the effect of $\mathrm{pH}$ on the antimicrobial activity of the CS composites, they were treated with varying $\mathrm{pH}$ solutions before exposure to the bacteria. Growth reductions were only seen with two bacteria, MRSA and $E$. coli [Fig. $7(E, F)]$. Both bacterial strains were inhibited the most by $100 \%$ CS material treated with the more acidic $\mathrm{pH}$ solutions, 3.5 and 5.0. These findings are consistent with the above figure showing that $100 \%$ CS material had the largest growth rate reduction and with previous studies demonstrating that CS prepared in acidic conditions have a greater antimicrobial effect on certain bacteria. ${ }^{44}$

The bacteria used in this study of CS composites are those found to have the highest morbidity and mortality associated with wound infections. It has been shown that the presence of CS in a wound dressing material has greater effects both in vitro and in vivo than other types of nonCS wound treatments. ${ }^{5}$ Ignatova et al. demonstrated the antibacterial properties of electrospun mats of quaternized CS killed bacteria, especially $S$. aureus and E. coli within $2 \mathrm{~h} .{ }^{41} \mathrm{In}$ this study, we have shown the inhibition of growth of both gram positive (MRSA, S. aureus, and Enterococcus) and gram negative (E. coli) bacteria by the prepared CS composites over 24 h. Previous antibacterial inhibition studies by Cai et al. showed an inhibition of $E$. coli growth, but not with $S$. aureus with a CS/silk fibroin composite, ${ }^{45}$ as we have shown an inhibition effect on multiple organisms. Bacteriostatic and bacteriocidal properties are important for wound healing applications in preventing infection 
and even possible sepsis. The non-pH treated CS demonstrated the ability to inhibit growth with a greater range of bacteria. Although the $\mathrm{pH}$ treated CS composites had a very high effect with $E$. coli. These effects of the CS composites on the wound pathogens illustrate their great potential as components in wound dressings.

\section{CONCLUSIONS}

In summary, we have successfully developed a simple and totally recyclable method to synthesize novel, high performance, biocompatible, and biodegradable composite materials from CEL and CS. In this method, $\left[\mathrm{BMIm}^{+} \mathrm{Cl}^{-}\right.$], an ionic liquid (IL), was used as a green solvent to dissolve and synthesize the [CEL+CS] composite materials. Since, the IL can be removed from the composite materials by washing them with water, and recovered by distilling the washed solution, the method is totally recyclable. Various spectroscopic and imaging techniques including XRD, FTIR, NIR, and scanning electron microscope were used to monitor the dissolution process, to characterize the composite material and to confirm that CEL and CS were successfully regenerated by the method. We have successfully demonstrated that [CEL+CS] composite material exhibits strong antimicrobial activity toward many different bacteria. This is because the [CEL+CS] composite material have combined advantages of their components, namely superior chemical stability and mechanical stability (from CEL) and bactericide (from CS). Specifically, results of tensile strength measurements clearly indicate that adding CEL into CS substantially increase its tensile strength. Up to $5 \times$ increase in tensile strength can be achieved by adding $80 \%$ of CEL into CS, and that the tensile strength of the composite material can be adjusted to any value by adding judicious amount of CEL. More importantly, the tensile strengths of [CS+CEL] composite materials are comparable with those of existing CS based materials including those prepared by either grafting or covalently attaching CS to man-made polymers. Results of in vitro antibacterial assays confirm that unique properties of CS remain intact in the material, namely, the composite material retain its antibacterial property. More importantly, the [CEL+CS] composite materials prepared using method reported here can inhibit growth of wider range of bacteria other than CS based materials prepared by conventional methods, namely, it was found that over $24 \mathrm{~h}$ period, the [CEL+CS] composite materials substantially inhibited growth of bacteria such as MRSA, VRE, S. aureus, and E. coli. These are bacteria that are often found to have the highest morbidity and mortality associated with wound infections.

\section{Supporting Information}

Additional Supporting Information may be found in the online version of this article.

\begin{tabular}{|l|l|}
\hline Filename & Description \\
\hline JBM_34520_sm_Supplnfo.docx599.7 KB & Supporting Information \\
\hline
\end{tabular}

Please note: The publisher is not responsible for the content or functionality of any supporting information supplied by the authors. Any queries (other than missing content) should be directed to the corresponding author for the article.

\section{REFERENCES}

1. Dai T, Tegos GP, Barkatovskaya M, Castano AP, Hamblin MR. Chitosan acetate bandage as a topical antimicrobial dressing for infected burns. Antimicrobial Agents Chemo 2009; 53: 393- 400.

2. Bordenave N, Grelier S, Coma V. Hydrophobization and antimicrobial activity of chitosan and paperbased packaging materials. Biomacromolecules 2010; 11: 88- 96.

3. Rabea El, Badawy M, Stevens CV, Smagghe G, Steurbaut W. Chitosan as antimicrobial agent: Applications and mode of action. Biomacromolecules 2003; 4: 1457- 1465. 
4. Altiok D, Altiok E, Tihminlioglu F. Physical, antibacterial and antioxidant properties of chitosan films incorporated with thyme oil for potential wound healing applications. J Mater Sci: Mater Med 2010; 21: 2227- 2236.

5. Burkatovskaya M, Tegos GP, Swietlik E, Demidova TN, Castano AP, Hamblin MR. Use of chitosan bandage to prevent fatal infections developing from highly contaminated wounds in mice. Biomaterials 2006; 27: 4157-4164.

6. Kiyozumi T, Kanatani Y, Ishihara M, Saitoh D, Shimizu J, Yura H, Suzuki S, Okada Y, Kikuchi M. Medium (DMEM/F12)-containing chitosan hydrogel as adhesive and dressing in autologous skin grafts and accelerator in the healing process. J Biomed Mat Res B: Appl Biomater 2006; 79B: 129- 136.

7. Jain D, Banerjee R, Comparison of ciprofloxacin hydrochloride-loaded protein, lipid, and chitosan nanoparticles for drug delivery. J Biomed Mater Res B 2008; 86: 105- 112.

8. Varshosaz J, Tabbakhian M, Salmani Z. Designing of a thermosensitive chitosan/poloxamer in situ gel for ocular delivery of ciprofloxacin. Open Drug De J 2008; 2: 61- 70.

9. Naficy S, Razal JM, Spinks GM, Wallace GG. Modulated release of dexamethasone from chitosan-carbon nanotube films. Sensor Actuat A 2009; 155: 120-124.

10. Finkenstadt VL, Millane RP. Crystal Structure of Valonia Cellulose 1ß. Macromolecules 1998; 31: 77767783.

11. Augustine AV, Hudson SM, Cuculo JA. In: JF Kennedy, GO Philipps, PA Williams, editors. Aspects of cellulose structure. Cellulose Sources and Exploitation. New York: E. Horwood; 1990. p 59.

12. Dawsey TR. In: RD Gilbert, editor. Water Soluble Cellulose Derivatives and their Commercial Use. Cellulosic Polymers, Blends and Composites. New York: Carl Hanser Verlag; 1994. p 157.

13. Cai J, Liu Y, Zhang L. Dilute solution properties of cellulose in LiOH/urea aqueous system. J Polym Sci B: Polym Phys 2006; 44: 3093- 3101.

14. Fink HP, Weigel P, Purz HJ, Ganster J. Structure formation of regenerated cellulose materials from NMMO-solutions. Prog Polym Sci 2001; 26: 1473- 1524.

15. Miao J, Zhang F, Takieddin M, Mousa S, Linhardt RJ. Adsorption of doxorubicin on poly(methyl methacrylate)-chitosan-heparin-coated activated carbon beads. Langmuir 2012; 28: 4396- 4403.

16. McCarthy SJ, Gregory KW, Morgan JW. Tissue dressing assemblies systems, and methods formed from hydrophilic polymer sponge structures such as chitosan. WO Patent No. 062896, 2005.

17. El-Mekawy A, Hudson S, El-Baz A, Hamza H, El-Halafawy K. Preparation of chitosan films mixed with superabsorbent polymer and evaluation of its haemostatic and antibacterial activities. J Appl Polym Sci 2010; 116: 3489- 3496.

18. Sandoval M, Albornoz C, Munoz S, Fica M, Garcia-Huidobro I, Mertens R, Hasson A. Addition of chitosan may improve the treatment efficacy of triple bandage and compression in the treatment of venous leg ulcers. J Drugs Dermatol 2010; 10: 75- 80.

19. Jayakumar R, Prabaharan M, Sudheesh PT, Nair SV, Tamura H. Biomaterials based on chitin and chitosan in wound dressing applications. Biotech Adv 2011; 29: 322- 337.

20. Swatloski RP, Spear S, Holbrey JD, Rogers RD. Dissolution of cellulose in ionic liquids. J Am Chem Soc 2002; 124: 4974- 4975.

21. El Seould OA, Koschella A, Fidale LC, Dorn S, Heinze T. Applications of ionic liquids in carbohydrate chemistry: A window of opportunities. Biomacromolecules 2007; 8: 2629- 2647.

22. Pinkert A, Marsh KN, Pang S, Staiger MP. Ionic liquids and their interaction with cellulose. Chem Rev 2009; 109: 6712-6728.

23. Tran CD, Lacerda SHP. Determination of binding constants of cyclodextrins in room temperature ionic liquids by near-infrared spectrometry. Anal Chem 2002; 74: 5337- 5341.

24. Han X, Armstrong DW. Ionic liquids in separations. Acc Chem Res 2007; 40: 1079- 1086. 
25. Tran CD. Development of a Universal Method based on Ionic Liquids for Determination of Enantiomeric Compositions of Pharmaceutical Products. Ionic Liquids Applications: Pharmaceutical, Therapeutics and Biotechnology. In: S Maholtra, editor. ACS Symposium Series: American Chemical Society Publishing; 2010. p 35.

26. Welton T. Room-temperature ionic liquids. Solvents for synthesis and catalysis. Chem Rev 1999; 99 : 2071- 2083.

27. Wasserscheid P, Welton T. Ionic Liquids in Synthesis. Weinheim, Germany: Wiley-VCH; 2003.

28. Soukup-Hein RJ, Warnke MM, Armstrong DW. Ionic liquids in analytical chemistry. Ann Rev Anal Chem 2009; 2: 145- 168.

29. Tran CD. Ionic Liquids for and by Analytical Chemistry. Anal Lett 2007; 40: 2447- 2464.

30. Baptista MS, Gao GH. Near infrared detection of flow injection analysis by acousto-optic tunable filter based spectrophotometry. Anal Chem 1996; 68: 971- 976.

31. Tran CD, Kong X. Determination of identity and sequences of tri- and tetrapeptides by near-infrared spectrometry. Anal Biochem 2000; 286: 67- 74.

32. Frez C, Diebold G, Tran CD, Yu S. Determination of thermal conductivities, thermal diffusivities, and sound speeds of room temperature ionic liquids by transient grating technique. J Chem Eng Data 2006; 54: $1250-1255$.

33. Tran CD, Lacerda SP, Oliveira D. Absorption of water by room-temperature ionic liquids: Affect of anions on concentration and states of water. App/ Spectrosc 2003; 57: 152- 157.

34. Docherty KM, Kulpa CF. Toxicity and antimicrobial activity of imidazolium and pyridinium ionic liquids. Green Chem 2005; 7: 185- 189.

35. Ropel L, Belveze LS, Aki, SNVK, Stadtherr MA, Brennecke JF. Octanol-water partition coefficients of imidazolium-based ionic liquids. Green Chem 2005; 7: 83.

36. Da Roz AL, Leite FL, Pereiro LV, Nascente PAP, Zucolotto V, Oliveira ON, Jr, Carvalho AJF. Adsorption of chitosan on spin-coated cellulose films. Carbohydr Polym 2010; 80: 65- 70.

37. Dreve S, Kacso I, Bratu I, Indrea E. Chitosan-based delivery systems for diclofenac delivery: Preparation and characterization. J Phys Conference Series 2009; 182: 1- 4.

38. Ellis JW. Infra-red absorption by the N-H bond II in aryl, alkyl and aryl-alkyl amines. J Am Chem Soc 1928; 50: 685-695.

39. Kiuchi H, Weihua K, Yoshio I. Preparation and characterization of poly(ethylene glycol) crosslinked chitosan films. J Appl Polym Sci 2008; 107: 3823-3830.

40. Liang S, Liu L, Huang Q, Yam KL. Preparation of single or double-network chitosan/poly(vinyl alcohol) gel films through selectively cross-linking method. Carbohydr Polym 2009; 77: 718- 724.

41. Ignatova M, Starbova K, Markova N, Naolova N, Rashkov I. Electrospun nano-fibre mats with antibacterial properties from quarternized chitosan and poly(vinyl alcohol). Carbohydr Res 2006; 341: 2098- 2107.

42. Radhakumary C, Nair PD, Nair CP, Mathew S. Chitosan-comb-graft-polyethylene glycol monomethacrylate-synthesis, characterization, and evaluation as a biomaterial for hemodialysis applications. J Appl Polym Sci 2009; 114: 2873- 2886.

43. Rabea El, Badawy ME-T, Stevens CV, Smagghe G, Steurbaut W. Chitosan as antimicrobial agent: Applications and mode of action. Biomacromolecules 2003; 4: 1457- 1465.

44. Jayakumar R, Prabaharan M, Sudheesh Kumar PT, Nair SV, Tamura H. Biomaterials based on chitin and chitosan in wound dressing applications. Biotechnol Adv 2011; doi: 10.1016/j.biotechadv.2011.01.005.

45. Cai Z, Mo X, Zhang K, Fan L, Yin A, He C, Wang H. Fabrication of chitosan/silk fibroin composite nanofibers for wound dressing applications. Int J Mol Sci 2010; 11: 3529- 3539. 